\title{
ARENIZAÇÃO: VISÃO E PRÁTICAS DOS TÉCNICOS E GESTORES NO SUDOESTE DO RIO GRANDE DO SUL
}

\author{
José Carlos Corrêa Ribeiro ${ }^{1} \&$ Roberto Verdum² \\ ${ }^{1}$ Prof. Ms. Geógrrafo. Doutorando em Geografia - UFRGS - E-mail: zecaribeiro@gmail.com. \\ ${ }^{2}$ Prof. Dr. Geógrafo. Departamento de Geografia - UFRGS - E-mail: rverdum@ufrgs.com.
}

\begin{abstract}
Resumo: Desde a década de 1970, a arenização e a silvicultura vêm ocupando as pautas das políticas ambientais referentes à região Sudoeste do Rio Grande do Sul, perpassando diversos segmentos da sociedade, entre comunidades locais de agricultores e pecuaristas, técnicos e políticos. 0 presente artigo tem por objetivo demonstrar algumas das visões dos técnicos e gestores locais em relação à arenização, bem como as práticas de conservação do solo preconizadas por eles. Para a obtenção dessas informações, foram realizadas entrevistas estruturadas com trinta e nove técnicos de quinze municípios: Alegrete, Manoel Viana, Maçambará, Quaraí, Rosário do Sul, Cacequi, Itaqui, Santiago, Unistalda, Jaguari, Santa Maria, Santana do Livramento, São Borja e Uruguaiana. Dentre os resultados da pesquisa, foi identificada a generalizada recomendação do plantio de arbóreas, como o eucalipto, e pastagens exóticas pelos técnicos e gestores locais.
\end{abstract}

Palavras chave: arenização - silvicultura - políticas ambientais - conservação do solo.

\section{Introdução}

O presente artigo objetiva a demonstração de dados parciais sobre as visões e preconizações, por parte dos técnicos e gestores públicos, em relação ao processo de arenização que ocorre no sudoeste do Rio Grande do Sul. São aqui abordados resultados parciais da aplicação de perguntas na forma de entrevista estruturada, em alguns casos de controle e pré-teste, e na forma de questionários, aplicados a um número maior de respondentes. Tendo sido pré-testado presencialmente em cinco escritórios municipais da Associação
Riograndense de Empreendimentos de Assistência Técnica e Extensão Rural - EMATER RS, os formulários ajustados foram enviados para escritórios da EMATER em outros municípios, secretarias municipais de agricultura, meio ambiente e outras, escolas técnicas, sindicatos rurais, comitês de bacia hidrográfica, consultores locais, associações de municípios, etc, em 15 municípios da região da Campanha: Alegrete, Manoel Viana, Maçambará, Quaraí, Rosário do Sul, Cacequi, Itaqui, Santiago, Unistalda, Jaguari, Santa Maria, Santana do Livramento, São Borja, Uruguaiana - Figura 1.

Figura 1 - Mapa de Localização dos municípios pesquisados.

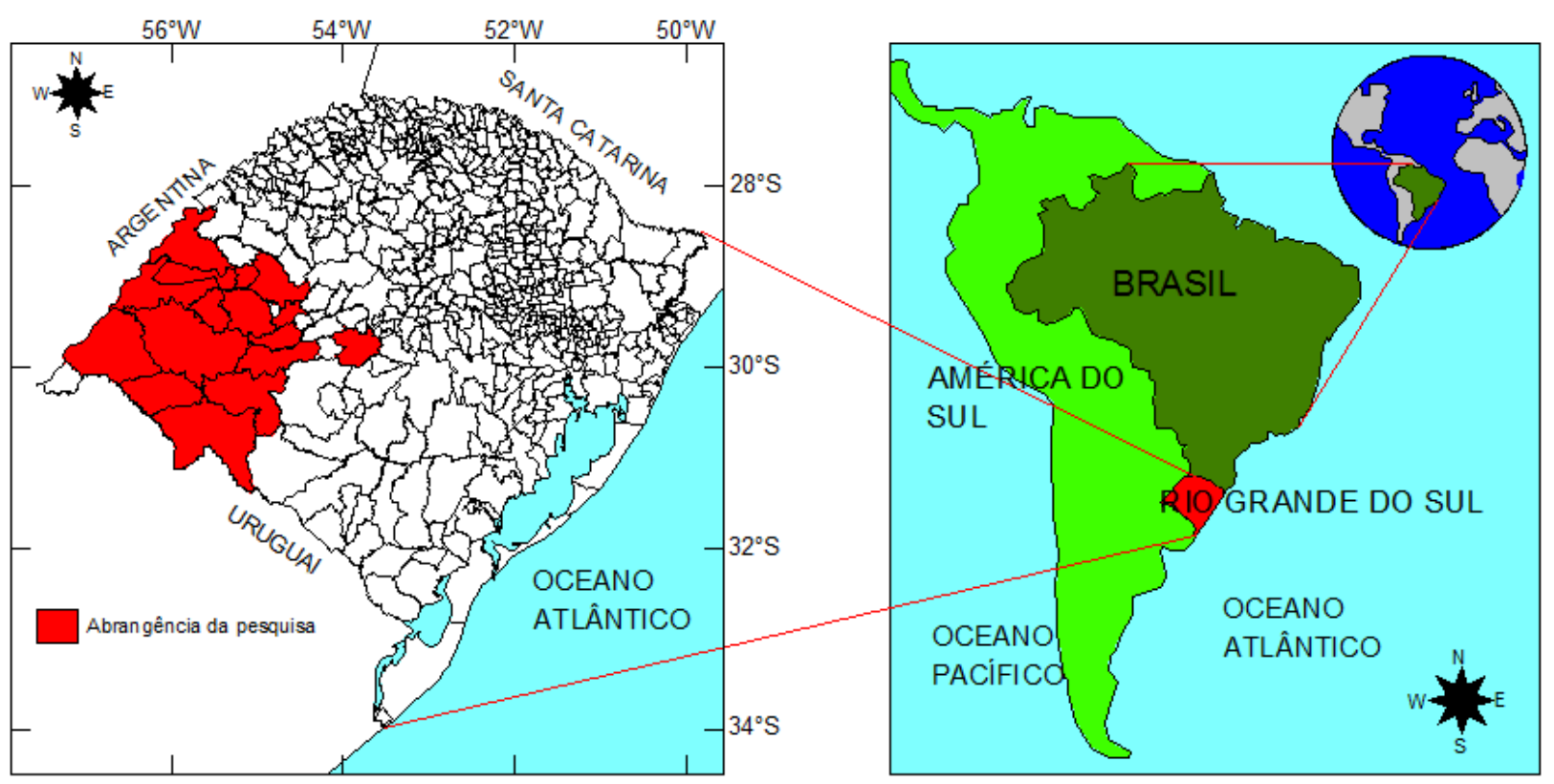


Também foram realizadas visitas aos quatro municípios onde existem projetos de recuperação de áreas degradadas pela arenização: Alegrete, Manoel Viana, Maçambará e São Francisco de Assis. Nesses municípios foi possível constatar uma generalizada preferência pela adoção do plantio de Eucalipto e forrageiras como proposição técnica. Nessas visitas, foram coletados documentos referentes a projetos voltados para a "recuperação de áreas degradadas pela arenização", como são tratadas. 0 conteúdo desses projetos, considerados exemplos das Políticas Públicas de abrangência local, foi analisado. 0 leitor vai perceber uma forte consistência entre as formulações e proposições apresentadas nas Políticas Públicas aqui apresentadas e as opiniões dos gestores e técnicos locais coletadas em entrevistas e questionários.

\section{Contexto do debate sobre "desertificação" e as pro- postas de recuperação}

A arenização, processo morfogenético que conduz a formação dos areais, é vista como "um dos processos mais intensos de degradação ambiental que ocorrem na região da fronteira oeste do Estado" (BERTÊ, 2004) atingindo dez municípios na região, sendo mais significativo em Alegrete, Maçambará, Manuel Viana, Quaraí e São Francisco de Assis, onde as áreas arenizadas variam em torno de 1\% de seus territórios (SUERTEGARAY, GUASSELI E VERDUM, 2001).

A partir da década de 1970 o Sudoeste do Rio Grande do Sul passa a ser visto como "região sujeita à desertificação" (sic), em razão, principalmente, dos artigos científicos e reportagens que criam um clima de alarmismo em torno da arenização. Dentre as formulações científicas que mais contribuíram para o alarmismo em torno da "desertificação", e para o estigma negativo do Homem do campo, se destaca o trabalho de Souto (1985) que atribuía origem humana ao processo de "desertificação" no sudoeste do Rio Grande do Sul, apontando o superpastoreio e a mecanização das lavouras como "ações antrópicas responsáveis". 0 mais importante contraponto para essa concepção a respeito dos areais é o trabalho de Suertegaray (1987) que desmistifica e relativiza algumas ideias propaladas na época, a exemplo da noção de "desertificação" e sua gênese humana. Em oposição à ideia de "deserto", a autora resgatou topônimos locais como "Areal" e "Rincão do Areal".

As primeiras propostas de "recuperação dos areais" tiveram início através da Secretaria de Agricultura do Estado do Rio Grande do Sul, com o Plano Piloto de Alegrete, que consistia na instalação de quebra-ventos e plantio de espécies arbóreas e arbustivas, leguminosas e gramíneas. Desse plano piloto resultou a conclusão de que a espécie que melhor se desenvolvia sobre os areais era o eucalipto (SOUTO, 1985). Entre o final da década de 1980 e início da década de 1990, por iniciativa privada (RIOCELL S/A e TANAC S/A), in- termediada pelo Governo do Estado do Rio Grande do Sul, surgem tentativas de recuperação dos areais, mediante o plantio de eucalipto e acácia negra. 0 convênio firmado consistiu na continuidade do Plano Piloto do Alegrete. Em 2007, um novo empreendimento florestal - a suecofinlandesa Stora Enso - é atraído para o estado, realizando o plantio de 100 mil ha. de eucalipto em onze municípios da região dos areais.

\section{Perfil dos respondentes da pesquisa}

Foram aplicados pré-testes do questionário nos cinco municípios mais atingidos pelos processos de arenização (Alegrete, Manoel Viana, São Francisco de Assis, Maçambará e Quaraí) e, após este pré-teste, foram enviados questionários para os técnicos e gestores públicos dos demais municípios onde ocorre a arenização e outros municípios da região. Foram incluídos municípios, onde não ocorre o processo de arenização, mas que são centros de referência, como Santa Maria, ou municípios dos quais se emanciparam municípios onde ocorre o processo, como Santiago. Os respondentes da pesquisa atuam, majoritariamente, em quatro municípios: Alegrete (25,6\%), Manoel Viana $(17,9 \%)$, São Francisco de Assis $(15,4 \%)$ e Maçambará $(10,3 \%)$. Este grupo de municípios corresponde a $69,2 \%$ dos municípios de atuação dos respondentes da pesquisa. Cabe ressaltar que a grande concentração de respondentes nesses quatro municípios não é proposital. São esses os municípios que, de fato, mais concentram técnicos e gestores engajados na temática da "recuperação de áreas degradadas" pela arenização. Os demais municípios, 30,8\% dos respondentes, incluem: Rosário do Sul, Cacequi, Itaqui, Santiago, Unistalda, Jaguari, Santa Maria, Santana do Livramento, São Borja, Uruguaiana, e outros.

Os respondentes têm idade média de 48 anos. Idade mínima de 21 anos e máxima de 70 anos. Mais da metade $(61,5 \%)$ tem idade entre 41 e 60 anos. Quanto ao tempo de atuação na atual ocupação profissional: $36,8 \%$ têm menos de cinco anos de atuação; 10,5\% têm entre seis e 10 anos de atuação no cargo atual; $26 \%$ têm entre 11 e 20 anos no cargo atual; 10,5\% têm entre 21 e 30 anos no cargo atual; os veteranos $(15,8 \%)$ estão há mais de 30 anos na atual ocupação.

As entidades que os respondentes representam concentram-se na EMATER $(33,3 \%)$ e nos poderes Executivo e Legislativo municipal (Secretarias Municipais, de Agricultura e Meio Ambiente, e câmara de vereadores), que respondem juntos por 35,9\% dos respondentes. Dentre as demais instituições constam, ainda, as Universidades ou Escolas Técnicas (10,3\%), Sindicatos rurais $(7,7 \%)$, Associação de Municípios da Fronteira Oeste (AMFRO), Comitê de Bacia Hidrográfica do Rio Ibicuí, Fundação Marona, Serviço Nacional de Aprendizagem Rural (SENAR), Governo do Estado/Secretaria de Agricultura e ainda a empresa Stora Enso. Esses últimos, todos com um respondente, ou 2,6\% do total. 
A maioria dos respondentes é bastante atuante na comunidade, com destaque para a participação em ONGs (59\%), Sindicato rural (59\%) e Comitê de Bacia Hidrográfica $(56,4 \%)$. A participação partidária $(38,5 \%)$ é distribuída nas siglas: PP (4), PSDB (1), PDT (3), PT (1), PMDB (2), PFL (1) e outros partidos (3). Constam também na lista: Centros de Tradição Gaucha $(28,2 \%)$; Associação de moradores (25,6\%); Igreja (25,6\%); Maçonaria (12,8\%); Conselhos municipais (7,7\%); Conselho Regional de Engenharia e Agronomia - CREA/RS (5,1\%); Comissão Técnica Nacional de Biossegurança - CTBio (2,6\%); Lyons Club (2,6\%); Rotary Club $(2,6 \%)$ e Sindicato dos Engenheiros do RS - SENGE/RS (2,6\%).

Sobre a atuação em relação à recuperação de áreas em arenização, mais da metade $(64,1 \%)$ afirmou prestar aconselhamento ou assistência técnica (geralmente assistência a agricultores). Outros, utilizando resposta aberta, afirmaram divulgar informações $(10,3 \%)$, outros afirmaram atuar em sua propriedade $(12,8 \%)$. Esse grupo, dos que atuam de alguma forma na recuperação de areais, é formado por 29 respondentes $(74,4 \%)$. Cabe salientar que alguns respondentes optaram por mais de uma resposta, pois pode atuar em mais de uma modalidade (assistência técnica, divulgação, por exemplo). Dentre os que afirmaram não atuar de forma alguma, nove respondentes $(23,1 \%)$ afirmaram não atuar por não dispor de recursos. Nenhum respondente afirmou não atuar por não considerar a arenização um problema.

Os respondentes apresentaram elevada formação escolar. 0 número de pós-graduados $(46,2 \%)$ supera o número de somente graduados $(35,9 \%)$. Os que cursaram somente o Técnico Agrícola respondem por 12,8\% dos respondentes, no entanto, entre os pós-graduados também constam dois que passaram pelo curso técnico Agrícola, mas que não são contabilizados.

Quanto à área de formação e/ou profissão, destacam-se as ciências do solo. Somente a Agronomia (38,5\%), Técnico Agrícola (17,9\%) totalizam 22 dos 39 respondentes, ou seja, 56,4\% desses. Somando-se a Engenharia Florestal $(10,3 \%)$ chega-se a dois terços dos respondentes $(66,7 \%)$. Dentre as demais formações, que totalizam um terço dos respondentes, constam: En- sino Médio (5,1\%), Med. Veterinária (5,1\%),, Zootecnia $(5,1 \%)$, Biologia $(2,6 \%)$, Técnico em Gestão Ambiental (2,6\%), Engenharia Ambiental (2,6\%), Engharia Mecânica $(2,6 \%)$, Ciências Contábeis $(2,6 \%)$, Direito $(2,6 \%)$ e Jornalismo $(2,6 \%)$.

Dentre as instituições de formação dos respondentes da pesquisa, destacam-se as instituições federais de educação superior: Universidade Federal de Santa Maria - UFSM (28,2\%), a Universidade Federal do Rio Grande do Sul - UFRGS (17,9\%) e o Instituto Federal Farroupilha - IFF (10,3\%). Essas instituições respondem juntas por $56,4 \%$ das instituições que formaram os respondentes da pesquisa. As demais instituições são: Universidade da Região da Campanha - URCAMP (7,7\%); Universidade Federal de Pelotas UFPEL (5,1\%); Universidade Norte do Paraná - UNOPAR $(5,1 \%)$; Universidade Regional Integrada do Alto Uruguai e das Missões - URI (5,1\%); Centro Universitário Franciscano - UNIFRA (2,6\%); Escola Técnica Senador Salgado Filho/Alegrete (2,6\%); Pontifícia Universidade Católica do Rio Grande do Sul - PUC RS (2,6\%); Universidade Estadual do Rio Grande do Sul - UERGS (2,6\%); Universidade Regional do Noroeste do Estado do Rio Grande do Sul - UNIJUI (2,6\%) e Outras instituições $(7,7 \%)$.

\section{Entendimentos sobre os processos erosivos por parte dos técnicos e gestores}

Os respondentes foram indagados: Qual desses (problemas) você considera o maior problema para a agricultura/pecuária no seu município, ou região? A resposta permitia a escolha de mais de uma das seis opções: "areais", "desertos", "assoreamento de rios/ riachos/sangas", "afloramento de rochas", "ravinas e voçorocas" e "outros". Dentre as respostas, onze respondentes $(28,2 \%)$ apontaram "Assoreamento de rios e riachos/arroios/sangas" e "Areais". "Ravinas e voçorocas" foi o terceiro maior problema apontado por 10 respondentes $(25,6 \%)$, seguido por "afloramentos de rochas" $(10,3 \%)$. Somente três respondentes $(7,7 \%)$ optaram por afirmar que os "desertos" são o maior problema para a agricultura e pecuária da região, Tabela 1.

Tabela 1 - Maiores problemas para a agricultura/pecuária no município ou região.

\begin{tabular}{lcc}
\hline \multicolumn{1}{c}{ Problemas para a agricultura/pecuária no município ou região } & $\mathbf{N}^{\mathbf{0}}$ & $\mathbf{\%}$ \\
\hline Areais & 11 & $28,2 \%$ \\
\hline Assoreamento & 11 & $28,2 \%$ \\
\hline Ravinas e Voçorocas & 10 & $25,6 \%$ \\
\hline Afloramentos de Rochas & 4 & $10,3 \%$ \\
\hline "Desertos" & 3 & $7,7 \%$ \\
\hline Uso do solo & 3 & $7,7 \%$ \\
\hline Desmatamento & 1 & $2,6 \%$ \\
\hline Nenhuma opção & 1 & $2,6 \%$ \\
\hline Outros & 5 & $12,8 \%$ \\
\hline
\end{tabular}


Dentre os que marcaram a opção "outros", três $(7,7 \%)$ aproveitaram, espontaneamente, este campo para apontar questões relacionadas ao "uso do solo", ou a "má conservação do solo"; um (2,6\%) aproveitou o campo para apontar o "desmatamento" como grande problema. Os outros cinco $(12,8 \%)$, apresentados na tabela, preencheram o campo com opções variadas: "o capim annoni"; "produtores descapitalizados"; "precipitações irregulares"; "lagarta e Ferrugem na Soja, carrapato nos bovinos"; "distribuição de energia elétrica"e; por fim, um respondeu que "todos os itens são problemas, mas nenhum fundamental".

Indagados sobre o quanto a arenização é preocupante, quase todos respondentes, 38 de 39, afirmaram que a arenização é motivo para algum tipo de preocupação. Num total de 19 respondentes (48,7\%) afirmaram que é "muito preocupante", outros 19 respondentes $(48,7 \%)$ afirmaram que "em alguns casos é preocupante". Nenhum respondente afirmou "em nada me preocupa a arenização", Tabela 2 .

Tabela 2 - Preocupação em relação a arenização.

\begin{tabular}{lcc}
\hline \multicolumn{1}{c}{ A arenização é algo: } & $\mathbf{N}^{\mathbf{0}}$ & $\mathbf{\%}$ \\
\hline Em alguns casos é preocupante & 19 & $48,7 \%$ \\
\hline Muito preocupante & 19 & $48,7 \%$ \\
\hline Em nada preocupam & 0 & $0,0 \%$ \\
\hline Outro & 1 & $2,6 \%$ \\
\hline
\end{tabular}

Os respondentes, também, foram indagados se: Existem desertos na sua região? As possibilidades de resposta eram: "sim, existem"; "existem, mas conheço por outro nome" "Não existem" e "outros". Dentre os 39 respondentes, $17(43,6 \%)$ afirmaram que "sim, existem", enquanto quatro $(10,3 \%)$ concordam que "não existem, mas podem se formar". Ou seja, 21 respondentes $(53,9 \%)$ consideraram a existência, real ou potencial, de "desertos", e assim os nomeiam. Outros nove respondentes $(23,1 \%)$ confirmam sua existência, mas nomeiam de outra forma - "áreas em arenização", ou "areais" - e associam claramente areais e desertos.
Sete respondentes $(17,9 \%)$ não hesitaram em escolher a opção "não existem".

$\mathrm{Na}$ categoria "outros", dois respondentes $(5,1 \%)$ aproveitaram o campo para fazer as seguintes afirmações: “Existem áreas denominadas 'em arenização' mas não são desertos, pois chove mais de $1700 \mathrm{~mm}$ por ano na região onde elas ocorrem"; "áreas de arenização". Somando-se essas últimas categorias - "existem, mas conheço por outro nome", "não existem" e "outros" - percebemos que quase metade $(46,1 \%)$ dos respondentes já aceitou a idéia de que não existem desertos no sudoeste do Rio Grande do Sul, Tabela 3.

Tabela 3 - Existem desertos na sua região?

\begin{tabular}{llc}
\hline \multicolumn{1}{c}{ Existem desertos na sua região? } & $\mathbf{N}^{\mathbf{0}}$ & $\mathbf{\%}$ \\
\hline Sim, existem & 17 & $43,6 \%$ \\
\hline Existem, mas conheço por outro nome & 9 & $23,1 \%$ \\
\hline Não existem & 7 & $17,9 \%$ \\
\hline Não existem, mas podem se formar & 4 & $10,3 \%$ \\
\hline Outros & 2 & $5,1 \%$ \\
\hline
\end{tabular}

Ao indagar - Você considera que os areais do Rio Grande do Sul têm origem NATURAL? - as opiniões polarizadas "sim, ou não" foram pouco menos da metade $(48,7 \%)$, com uma ligeira vantagem do sim $(30,8 \%)$ em relação ao "não" (17,9\%). Algumas das respostas abertas associadas ao "não" apontaram "o mau uso do solo" como causa dos areais. A categoria "depende", em primeiro lugar com 38,5\%, somada à categoria "outros" $(12,8 \%)$, totalizam mais da metade das respostas $51,3 \%$, Tabela 4 .

Tabela 4 - Origem dos areais.

\begin{tabular}{|c|c|c|}
\hline Os areais do RS têm origem NATURAL? & $\mathbf{N}^{\mathbf{0}}$ & $\%$ \\
\hline Depende & 15 & $38,5 \%$ \\
\hline Sim & 12 & $30,8 \%$ \\
\hline Não & 7 & $17,9 \%$ \\
\hline Outros & 5 & $12,8 \%$ \\
\hline
\end{tabular}


Alguns respondentes forneceram as seguintes respostas abertas: "depende, um pouco é natural, devido ao tipo de solo e clima"; "A origem é natural, mas o homem acelerou o processo", "segundo opinião pessoal, uns tem origem natural, afloramento de areia que existe sob o basalto que aumenta com a ação do vento, com a não conservação do solo em anos anteriores e a sucessiva utilização de arado/grade em cultivos de trigo/ soja"; "devido a rocha matriz, aspecto natural, porém o homem, sem critérios de manejo, acelera o processo"; "natural e antrópica", "muitas vezes mau uso do solo".

Ao indagar - Na sua região, os areais estão aumentando? - as respostas polarizadas (Sim, ou Não) empataram com $41 \%$ das respostas. Ou seja, $41 \%$ dos respondentes acredita que os areais estão aumentando. Mas a maioria (59\%), formada pelos que responderam "não", "depende" e "outros" não acredita que estejam aumentando, Tabela 5.

Tabela 5 - Os areais estão aumentando?

\begin{tabular}{lccc}
\hline & Na sua região, os areais estão aumentando? & $\mathbf{N}^{\mathbf{0}}$ & $\mathbf{\%}$ \\
\hline Sim & 16 & $41,0 \%$ \\
\hline Não & 16 & $41,0 \%$ \\
\hline Depende & 5 & $12,8 \%$ \\
\hline Outros & 2 & $5,1 \%$ \\
\hline
\end{tabular}

Indagados sobre - Quais desses "agentes" intensificam a formação de areais (ou desertos) na sua região/município? - os respondentes optaram por uma ou mais alternativas de resposta. Erosão causada pela Mecanização $(74,7 \%)$, pelo vento $(69,2 \%)$ e a pelo pastoreio $(66,7 \%)$ foram os agentes de intensificação da arenização mais apontados, seguidas da erosão causada pela água $(38,5 \%)$ e da drenagem de banhados (17,9\%), Tabela 6.

Tabela 6 - Agentes que intendificam a formação de areais/desertos.

\begin{tabular}{|c|c|c|}
\hline Agentes que intensificam a formação de areais/desertos & $\mathbf{N}^{\mathbf{0}}$ & $\%$ \\
\hline Mecanização & 29 & $74,4 \%$ \\
\hline Vento & 27 & $69,2 \%$ \\
\hline Pastoreio & 26 & $66,7 \%$ \\
\hline Água & 15 & $38,5 \%$ \\
\hline Drenagem de banhados & 7 & $17,9 \%$ \\
\hline
\end{tabular}

Percebe-se que os fatores mais importantes, na opinião dos respondentes da pesquisa, são antrópicos, a exceção do vento. Na fase de pré-teste, os respondentes, também, manifestaram que os agentes erosivos atuam de modo sinérgico. Agentes antrópicos, como o mau uso do solo, favorecem a ação do vento, por exemplo. Com base nisso a versão final do questionário passou a oferecer aos respondentes a possibilidade de escalonamento dos agentes de intensificação da arenização, segundo sua importância.

Indagados sobre - Quais desses "agentes" intensificam a formação de areais (ou desertos) na sua região/município, EM PRIMEIRO LUGAR?- Repete-se o ranking do gráfico anterior. A mecanização aparece em primeiro lugar (46\%), o vento em segundo lugar $(23,1 \%)$ e o pastoreio em terceiro $(17,9 \%)$, Tabela 7.

Tabela 7 - Agentes que intensificam a arenização - 1ํ LUGAR.

\begin{tabular}{lcc}
\hline \multicolumn{1}{c}{ Agentes que intensificam a arenização - 10 LUGAR } & $\mathbf{N}^{\mathbf{0}}$ & $\mathbf{\%}$ \\
\hline Mecanização & 18 & $46,2 \%$ \\
\hline Vento & 9 & $23,1 \%$ \\
\hline Pastoreio & 7 & $17,9 \%$ \\
\hline Água & 4 & $10,3 \%$ \\
\hline Drenagem de banhados & 1 & $2,6 \%$ \\
\hline
\end{tabular}

Técnicas recomendadas para o controle da arenização

Os respondentes foram indagados sobre: Quais dessas técnicas você recomendaria para o controle da erosão/arenização/desertificação? Dentre as opções de recomendações , o "plantio/semeadura de Eucalipto, pinus ou acácia" $(74,4 \%)$ foi a mais escolhida, seguida de "cercamento da área" (69,2\%) e "plan- tio/semeadura de forrageiras (Braquiárias, Pensacola, Pangola, etc.)" (66,7\%). 0 "plantio/semeadura de árvores nativas" (51,3\%) também teve boa aceitação e a "contenção de ravinas" foi a de menor adesão, Tabela 8. Na categoria "outros", um dos respondentes recomendou o "pastoreio rotativo no perímetro externo dá área e avançando para dentro dela" e outro recomendou o uso de "espécies adaptadas". 


\begin{tabular}{lcc}
\hline \multicolumn{1}{c}{ Técnicas recomendadas para o controle da arenização } & $\mathbf{N}^{\mathbf{0}}$ & $\mathbf{\%}$ \\
\hline Eucalipto, Pinus ou Acácia & 29 & $74,4 \%$ \\
\hline Cercamento da área & 27 & $69,2 \%$ \\
\hline Forrageiras (Braquiárias, Pensacola, Pangola, etc.) & 26 & $66,7 \%$ \\
\hline Árvores nativas & 20 & $51,3 \%$ \\
\hline Contenção de ravinas & 15 & $38,5 \%$ \\
\hline Outros & 2 & $5,1 \%$ \\
\hline
\end{tabular}

Durante a fase de pré-teste, os respondentes deixaram claro que não há uma técnica isolada capaz de recuperar as "áreas degradadas" pela arenização. Todos respondentes optaram por preconizar mais de uma técnica, pois no entendimento desses, funcionam em sinergia ou que se devem adotar "técnicas compostas de acordo com a origem do processo". 0 formulário permitiu, então, a escolha de mais de uma alternativa. Além disso, foi oferecida possibilidade de escalona- mento das respostas, apontando qual das técnicas deveria ser urilizada em primeiro lugar, em segundo lugar e terceiro lugar.

Indadagos sobre - Quais dessas técnicas de controle da erosão/arenização/desertificação você recomendaria em $1^{\circ}$ LUGAR?, os respondentes adotaram o "cercamento da área" $(48,7 \%)$ como a primeira medida a ser aplicada, seguida de "plantio de Eucalipto, Pinus ou Acácia" (20,5\%), Tabela 9.

Tabela 9 - Técnicas recomendadas para o controle da arenização - 1ํo lugar.

\begin{tabular}{lcc}
\hline \multicolumn{1}{c}{ Técnicas recomendadas para o controle da arenização - 10 lugar } & $\mathbf{N}^{\mathbf{0}}$ & $\mathbf{\%}$ \\
\hline Cercamento da área & 19 & $48,7 \%$ \\
\hline Eucalipto, Pinus ou Acácia & 8 & $20,5 \%$ \\
\hline Árvores nativas & 4 & $10,3 \%$ \\
\hline Forrageiras (Braquiárias, Pensacola, Pangola, etc.) & 4 & $10,3 \%$ \\
\hline Contenção de ravinas & 2 & $5,1 \%$ \\
\hline Outros & 2 & $5,1 \%$ \\
\hline
\end{tabular}

Indadagos sobre - Quais dessas técnicas de controle da erosão/arenização/desertificação você recomendaria em $2^{\circ}$ LUGAR?, os respondentes adotaram o "plantio/semeadura de forrageiras" (30,8\%) como a primeira medida a ser aplicada, seguida de "plantio/ semeadura de Eucalipto, Pinus ou Acácia”, Tabela 10.

Tabela 10 - Técnicas recomendadas para o controle da erosão/arenização - 2o lugar.

\begin{tabular}{lcc}
\hline \multicolumn{1}{c}{ Técnicas recomendadas para o controle da arenização - 2o lugar } & $\mathbf{N}^{\mathbf{0}}$ & $\mathbf{\%}$ \\
\hline Forrageiras (Braquiárias, Pensacola, Pangola, etc.) & 12 & $30,8 \%$ \\
\hline Eucalipto, Pinus ou Acácia & 11 & $28,2 \%$ \\
\hline Árvores nativas & 8 & $20,5 \%$ \\
\hline Cercamento da área & 3 & $7,7 \%$ \\
\hline Contenção de ravinas & 3 & $7,7 \%$ \\
\hline Não respondeu & 1 & $2,6 \%$ \\
\hline
\end{tabular}

Indadagos sobre - Quais dessas técnicas de controle da erosão/arenização/desertificação você recomendaria em $3^{\circ}$ LUGAR?, os respondentes adotaram o "plantio/semeadura de forrageiras" $(25,6 \%)$ como a primeira medida a ser aplicada, seguida de "plantio/ semeadura de árvores nativas" e "plantio/semeadura de Eucalipto, Pinus e Acácia", empatados na segunda posição (17,9\%), Tabela 11.

Tabela 11 - Técnicas recomendadas para o controle da erosão/arenização - 3olugar.

\begin{tabular}{lcc}
\hline \multicolumn{1}{c}{ Técnicas recomendadas para o controle da arenização - 3o lugar } & $\mathbf{N}^{\mathbf{0}}$ & $\mathbf{\%}$ \\
\hline Forrageiras (Braquiárias, Pensacola, Pangola, etc.) & 10 & $25,6 \%$ \\
\hline Árvores nativas & 7 & $17,9 \%$ \\
\hline Eucalipto, Pinus ou Acácia & 7 & $17,9 \%$ \\
\hline Cercamento da área & 6 & $15,4 \%$ \\
\hline Contenção de ravinas & 6 & $15,4 \%$ \\
\hline Não respondeu & 2 & $5,1 \%$ \\
\hline
\end{tabular}




\section{Projetos de recuperação dos areais nos municípios da região}

Em Alegrete ${ }^{1}$, a mais recente intenção do escritório da EMATER e das Secretarias de Agricultura e de Meio Ambiente do Município, em conjunto com os agricultores e outras instituições, é a recuperação do "Areal Costa Leite", localizado no Distrito do Jacaquá/ Alegrete. Houve também a colaboração da Universidade Federal de Santa Maria e da Fundação Marona no desenvolvimento do projeto. Ainda que não exista um projeto formalizado, ou completo, esses órgãos já realizaram algumas iniciativas. A mais notável delas é a distribuição de mudas de eucalipto entre os agricultores familiares que residem naquela localidade, por volta do ano de 2004. Segundo Técnico da EMATER, as mudas doadas são oriundas do viveiro municipal. A técnica utilizada, segundo o técnico da EMATER, consiste no plantio de "eucalipto no entorno do arreal e espécies nativas no meio", figuras 2 e 3 .

Figura 2 - Quebra-vento no areal Costa Leite.

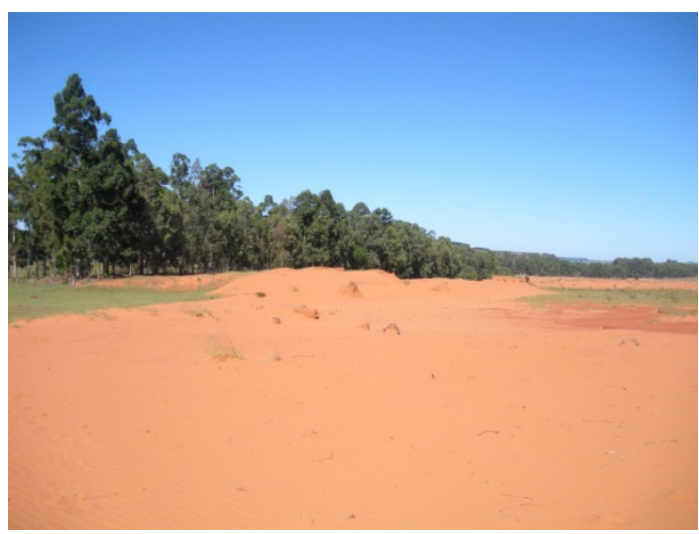

Fonte - o autor, 2013.

Figura 3. Quebra-vento no areal Costa Leite.

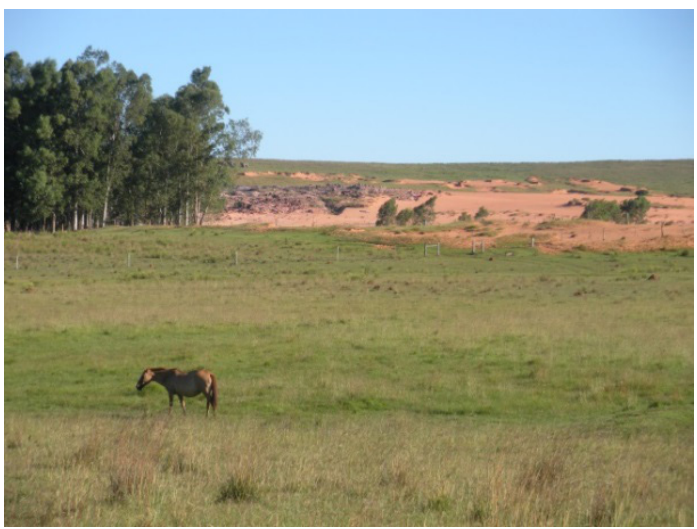

Fonte - o autor, 2013.

De acordo com informações da Secretaria de Agricultura do município, pretende-se retomar as ações de 2004. As secretarias municipais iniciaram tratativas junto à empresa do ramo florestal Stora Enso. Nesse acordo, a empresa forneceria as mudas de eucalipto, enquanto os agricultores contemplados pelo projeto ofereceriam mão-de-obra na coleta de sementes. 0 projeto não teve continuidade em razão de incertezas quanto à permanência da empresa StoraEnso no Estado. Tal incerteza se deve a questões como o Zoneamento Ambiental para a Silvicultura considerado demasiado restritivo pelas empresas do setor florestal e a pendência em relação à Faixa de Fronteira, de 150 km da linha de fronteira em direção ao interior do território, que restringe essa empresa sueco finlandesa de adquirir mais terras na região da Fronteira Oeste do Estado.

Também em Alegrete, consta o projeto denominado "Avaliação inicial do comportamento de espécies em solos suscetíveis à arenização no sudoeste do Rio Grande do Sul", desenvolvido pela Fundação Estadual de Pesquisa Agropecuária- FEPAGRO (2008) em regime de comodato, em uma área total de 12 hectares, no Distrito de São João. 0 projeto avaliou a sobrevivência e adaptação de espécies, principalmente, o Eucalipto e Acássia negra. 0 local escolhido para a instalação da Unidade Experimental, uma área de 12 hectares, está situado no Distrito de São João, município de Alegrete. 0 projeto foi desenvolvido em regime de comodato entre a FEPAGRO e a proprietária, denominada "comodante", Sra. Nair Braga de Vargas. Entre os objetivos do programa, são elencados: avaliar a sobrevivência e adaptação de espécies, medir seu desenvolvimento e quantificar a cobertura do solo, através da produção de serrapilheira produzida/hectare; analisar o efeito animal, em duas áreas representativas da realidade da região do Sudoeste do RS, área já arenizada e em processo de arenização; definir recomendações técnicas a serem adotadas pelos produtores rurais destas regiões a fim de conter 0 processo de arenização e; propor a recuperação e reintegração das áreas arenizadas ao processo produtivo, nas suas propriedades. Na primeira etapa, de um total de duas, foram utilizadas as seguintes espécies de árvores exóticas: Acaciamearnsii (acácia-negra) e Eucalyptusurograndis (Eucalyptusurophylla x Eucalyptusgrandis). Na segunda fase de implantação, foram utilizadas forrageiras perenes (pastagens): Panicummaximum cv. Aruana, Digitariadiversinervis, Mombaça, Brachiaria brizantha, Amendoim forrageiro e Axonopus jesuíta.

o município de Manoel Viana tem no assentamento Santa Maria do Ibicuí (INCRA - Instituto Nacional da Colonização e Reforma Agrária) o projeto mais persistente de controle da arenização realizado pelo escritório da EMATER. Em 2003 foi realizado um "projeto de pesquisa por demanda" denominado "validação e/ ou geração de tecnologias em manejo conservacionista para a recuperação de áreas em processo de degradação ou já degradadas, de solos com substrato arenito Botucatu na fronteira oeste" (EMATER/RS, 2003). Dentre os objetivos e as preconizações consta a utilização de plan-

${ }^{1}$ O mais importante projeto de combate aos processos erosivos em Alegrete foi o denominado Plano Piloto do Alegrete, desenvolvido pela Secretaria de Agricultura e Abastecimento do Governo do Estado do Rio Grande do Sul, entre as décadas de 1970 e 1990 . Este projeto, de influência regional, não é analisado no presente artigo, pois priorizamos analisar apenas os projetos de influência local. 
tas de cobertura e um experimento com um pequeno quebra-vento de eucalipto plantado em um dos areais do assentamento, figura 4 . No ano de 2009, um extensionista rural retoma a iniciativa da EMATER fazendo experimentos com "espécies adaptadas" de forrageiras nativas e exóticas, figura 5, e ainda elabora um PRAD Plano de Recuperação de Área Degradada (EMATER/RS, 2012) para o assentamento, visando à captação de recursos financeiros para recuperação dos areais.

Figura 4 - Quebra-vento de eucalipto plantado pela EMATER no assentamento Santa Maria do Ibicuí/Manoel Viana.

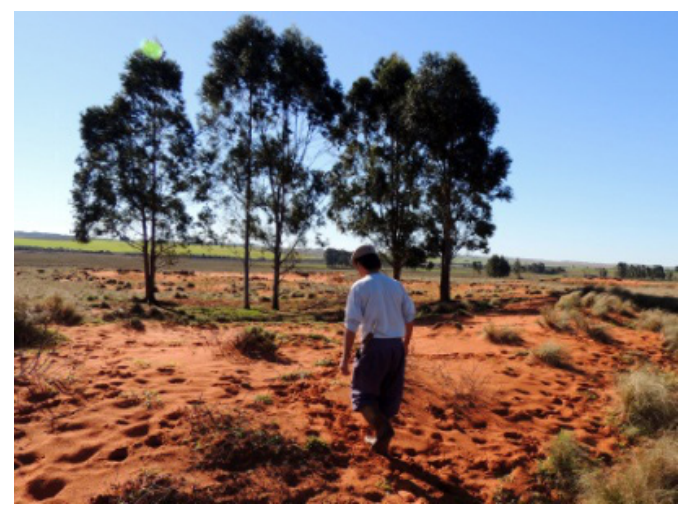

Figura 5 - Introdução do "capim-torpedo" pela EMATER no assentamento Santa Maria do Ibicuí/Manoel Viana.

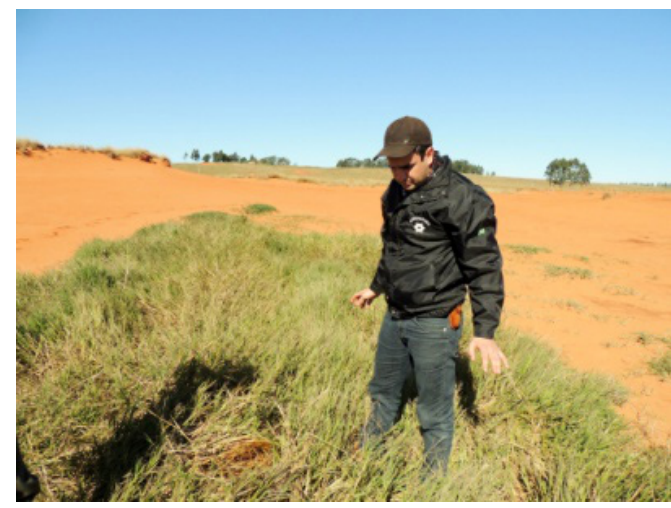

Em Maçambará, as principais ações têm como atores a empresa de celulose Stora Enso, Escola Técnica Estadual Encruzilhada, o Departamento Municipal de Meio Ambiente e o escritório municipal da EMATER. As ações, fomentadas pela empresa de celulose Stora Enso iniciaram a partir de 2007, quando da instalação das áreas de plantio da empresa na bacia do rio Puitã, localidade da Encruzilhada/Maçambará. A participação ativa da Stora Enso se faz presente na distribuição de mudas entre os proprietários rurais (Fomento florestal), onde ocorrem areais e, principalmente, no desenvolvimento de um experimento em parceria com a Escola Técnica Estadual da Encruzilhada, figuras 6 e 7. Nessa escola técnica é desenvolvido um projeto piloto de desenvolvimento de um sistema silvipastoril no qual as plantas clone de eucalipto são consorciadas ao plantio de forrageiras nas entrelinhas. De acordo com o Professor Sérgio Vezzosi Furguim, da Escola Técnica Estadual Encruzilhada, no experimento são comparadas espécies anuais (aveia, por exemplo) e pastagens nativas no consorciamento com o eucalipto.
Este experimento, assim como a distribuição de mudas, está inserido nos projetos da empresa StoraEnso, com os seguintes argumentos técnicos: aprimoramento de modelos de fomento florestal; capacitação e agregação de trabalhadores na silvicultura; integração com instituições atuantes na área de interesse; cooperação institucional para pesquisa e extensão; desenvolvimento de modelo de planejamento de propriedades para a silvicultura; entre outros. Esses projetos não visam somente a maximização do rendimento econômico do Empreendimento, mas a conformidade em relação ao rito do Licenciamento Ambiental, em acordo com a Resolução 237/1997 do Conselho Nacional de Meio Ambiente/CONAMA.

Figura 6 - Sistema silvipastorial em Maçambará.

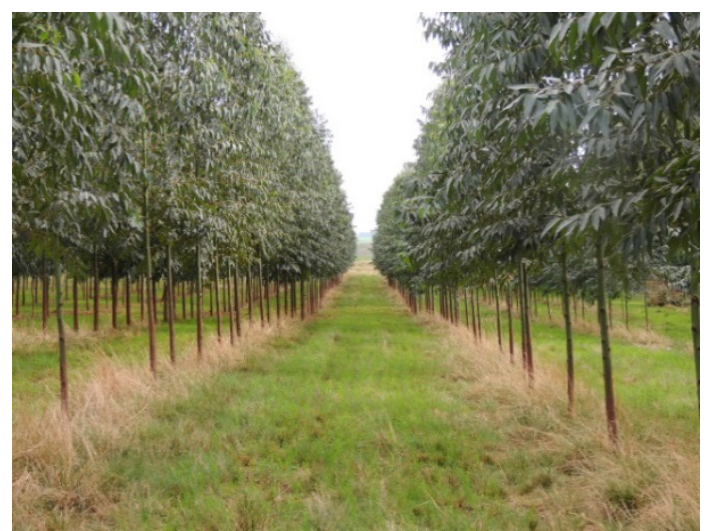

Fonte - o autor, 2013.

Figura 7 - Experimento com aveia e pastagens nativas no sistema silvipastoril em Maçambará.

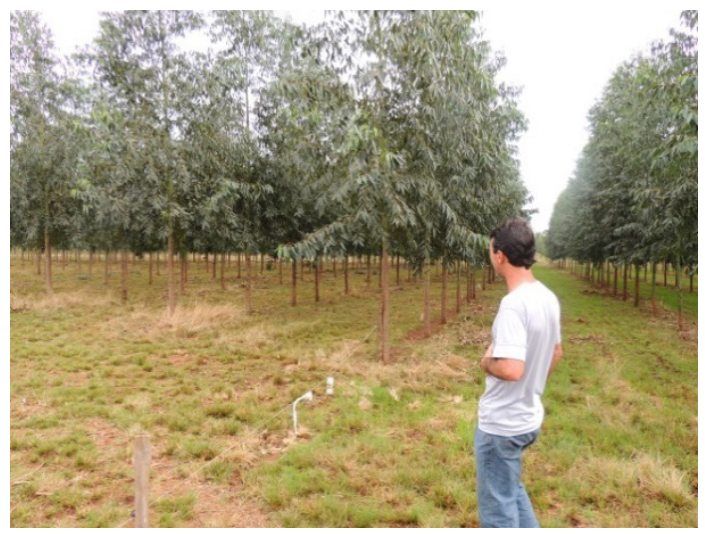

Fonte - o autor, 2013.

No município de São Francisco de Assis, durante a década de 1990, a municipalidade intentou super as dificuldades produtivas no interior do $5^{\circ}$ distrito da Vila Kraemer, por meio da adoção do "Plano de Manejo Integrado da Microbaciahidrográfica Sanga da Areia (Rio Grande do Sul, 1992). Segundo os técnicos do PMIMSA, a microbacia apresentava no ano de 1992, 1.308 hectares $(13,49 \%)$ de "áreas desertificadas". Por "desertificação dos solos" esses técnicos compreendem a "perda de suas propriedades físicas, químicas e biológicas". E sua origem, para os técnicos, é antrópica. Eles argumentam, ainda, que "o cultivo da soja e do trigo na década de 1970, sem a utilização das técnicas de uso, manejo e 
conservação do solo, causaram a formação de profundas vossorocas e acentuaram a desertificação do solo" (Rio Grande do Sul, 1992, pag. 13). Dentre as preconizações legadas pelo PMIMSA constam sugestões para o uso, manejo e conservação do solo, também as campanhas de conservação do solo e campanha de reflorestamento, além de outras. 0 florestamento é preconizado para a microbacia, bem como a implantação de viveiros de mudas com eucalipto, junto aos agricultores. 0 objetivo dessa orientação é a inserção da microbacia em uma nova matriz econômica, além do aproveitamento energético e para o consumo da propriedade.

Também em São Francisco de Assis, outras ações de recuperação de áreas arenizadas, além da redação do Plano de Manejo da Microbacia da Areia. De acordo com Mósena (2006) e Ribeiro (2008) a década de 1990 marcou a bacia hidrográfica da Sanga da Areia por profundas modificações na paisagem local, ocasionadas pela adoção de novas práticas de aproveitamento e conservação do solo. Exemplo disso foi a introdução das pastagens temporárias e exóticas (principalmente, a braquiária e a pangola), dos cultivos de soja (verão) e aveia (inverno) em sucessão e, ainda, a proliferação de capões de eucalipto, utilizados para o consumo próprio de madeira e uma utilização industrial, ainda incipiente. Nesse contexto, uma experiência bastante peculiar foi realizada na bacia hidrográfica Sanga da Areia - a fazenda de Miron Beck, palco de iniciativas da EMATER, em associação com o proprietário - Miron Beck. A propriedade, de 1.270 hectares, teria sido adquirida no ano de 1991 pelo agricultor, vindo do município de Três de Maio, região do Planalto do Estado. Elevados investimentos diferem essa das demais propriedades da bacia hidrográfica da Sanga da Areia. A parceria informal da EMATER com o proprietário foi um caso local de combate aos processos erosivos e silvicultura e, já no ano de 1993, a EMATER de São Francisco de Assis organizou uma saída de campo na propriedade de Miron Beck para mais de 200 proprietários rurais do município. Na ocasião, técnicos fizeram palestras sobre: solos, controle de voçorocas, plantio de forrageiras (Brachiária e Pangola), plantio de pinus e eucalipto e tratamento de madeiras, figuras 8 e 9.

Figura 8. Palestras sobreconservação do solo na fazenda de Miron Beck.

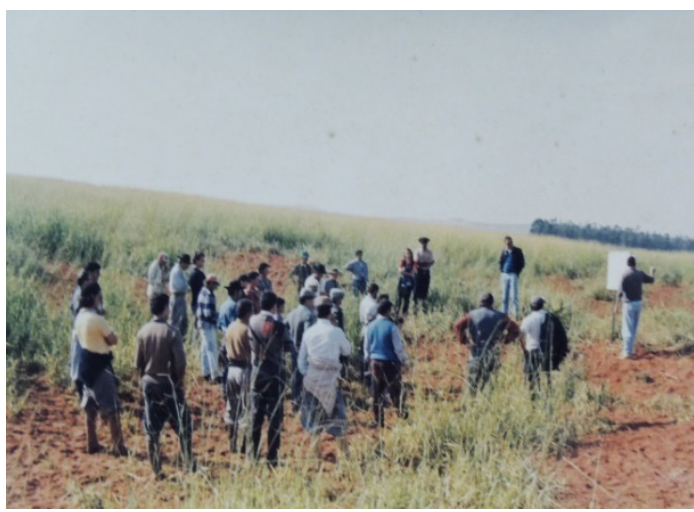

Fonte - EMATER, SãoFco. De Assis, 1993.
Figura 9 - Palestra sobre aproveitamento da madeira na Faz. Miron Beck.

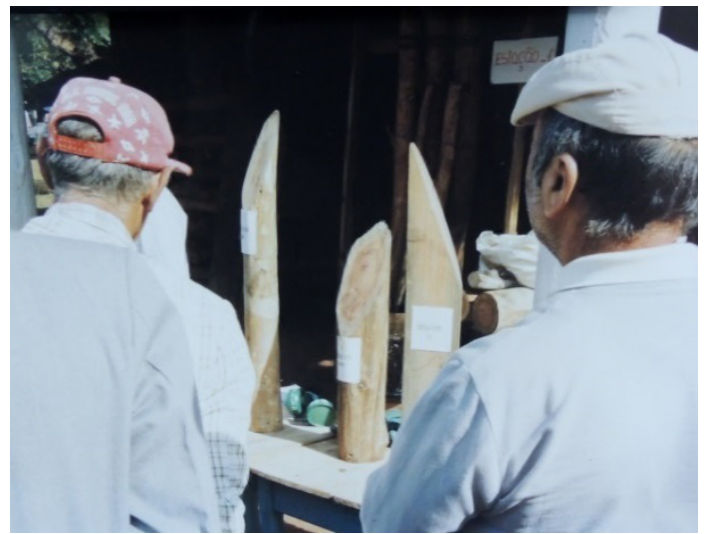

Fonte - EMATER, SãoFco. De Assis, 1993.

De acordo com Mósena (2006), a Fazenda de Miron Beck dedicava, no início da década passada, 500 hectares ao pastoreio de 280 cabeças de gado bovino, lotação possível graças ao plantio de pastagem cultivada (Braquiária), figura 6. Em outra área, de 180 hectares, cultivava soja e aveia em sucessão. Nas áreas recobertas por areia, o proprietário plantou um milhão de pés de eucalipto para uso industrial e para contenção da arenização, figuras 10 e 11.figura

Figura 10. Plantio de Braquiária, no primeiro plano, e Eucalipto, no segundo plano, na Fazenda Miron Beck/São Francisco de Assis.

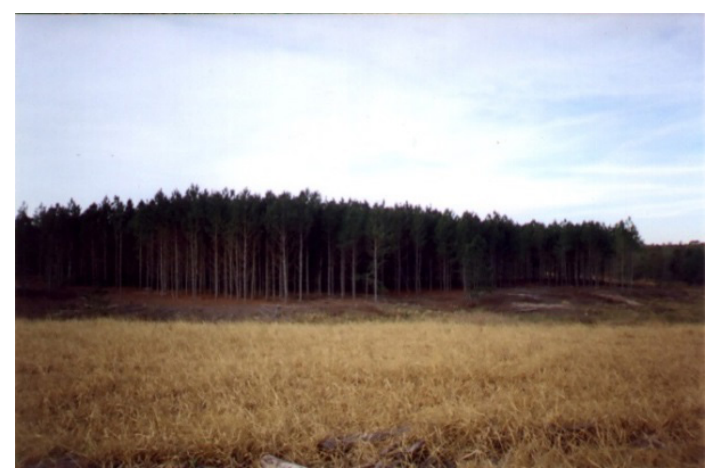

Fonte - o autor, 2007.

Figura 11. Plantio de eucalipto na Faz. Miron Beck/São Francisco de Assis.

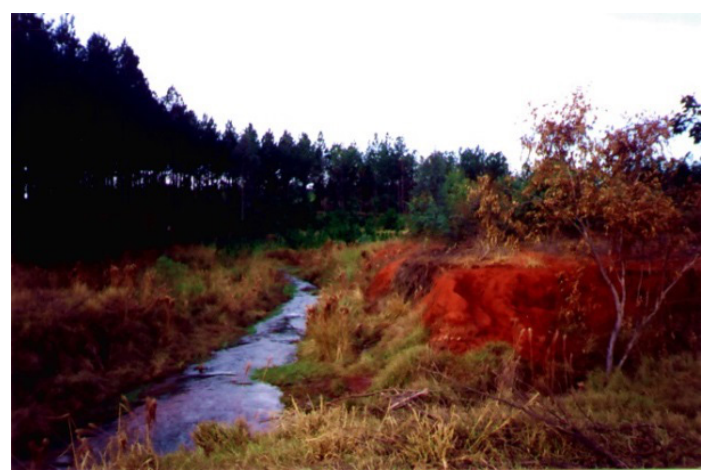

Fonte - o autor, 2007.

\section{Considerações finais}

As informações aqui apresentadas consistem em uma visão parcial e, ainda, em desenvolvimento. Buscou- 
-se demonstrar uma prévia em relação ao modo como os técnicos que fazem a gestão dos areais concebem o processo de arenização e como isso está relacionado com as práticas e preconizações. A aplicação de questionários, e a observação das preconizações presentes nos principais projetos desenvolvidos no âmbito municipal, mostrou que tanto os técnicos, quanto os gestores ligados ao meio político, compartilham das mesmas visões em relação aos processos erosivos e quanto às preconizações voltadas para o controle desses processos. 0 fato de maioria dos respondentes da pesquisa ter formação acadêmica nas ciências agrárias, independente de atuar como técnico, ou como político, é causador da hegemonia do discurso científico de forte viés agronômico por parte dos mediadores locais e regionais engajados na temática da arenização. A noção de que a arenização é um grave problema ambiental e de produtividade agrícola é compartilhada pelos respondentes em sua maioria. Também a ampla preconização, por parte dos gestores públicos e técnicos, do plantio de espécies arbóreas exóticas (Eucalipto e Acácia Negra) e de forrageiras (Braquiária) coincide com os experimentos realizados por centros de referência regionais. Na consecução da pesquisa, pretende-se demonstrar como as políticas públicas, a exemplo do Plano Piloto do Alegrete, foram determinantes na formulação das representações sobre os areais, colaborando para a difusão de um discurso científico de viés agronômico. Desse modo, pretende-se demonstrar, além da repercussão das políticas públicas e das formulações científicas e técnicas associadas sobre as práticas locais, como se constituiu o espaço social em relação à questão dos areais e da silvicultura como política associada.

\section{Referências}

BERTÊ, Ana Maria de Aveline. Problemas ambientais no Rio Grande do Sul. In: VERDUM, Roberto; BASSO, L. A.; SUERTEGARAY, D. M. A. (Org.). Rio Grande do Sul: paisagens e territórios em transformação. Porto Alegre: UFRGS, 2004. p. 61-70.

Rio Grande do Sul. Plano de Manejo Integrado da Microbacia Hidrográfica Sanga d'Areia. São Francisco de Assis.1992.
EMATER/RS - Empresa Riograndense de assistência técnica e extensão rural. Rio Grande do Sul. Validação e/ou geração de tecnologias em manejo conservacionista para a recuperação de áreas em processo de degradação ou já degradadas, de solos com substrato arenito Botucatu na fronteira oeste. EMATER/RS, 2003.

EMATER/RS - Empresa Riograndense de assistência técnica e extensão rural. Rio Grande do Sul. Projeto de recuperação de áreas degradadas no núcleo fronteira oeste no PA Santa Maria do Ibicuí em Manoel Viana/ RS. EMATER/RS - Escritório Manoel Viana, 2012.

FEPAGRO - Fundação Estadual de Pesquisa Agropecuária. Projeto de pesquisa avaliação inicial do comportamento de espécies em solos suscetíveis à arenização no sudoeste do Rio Grande do Sul. http://www.fepagro.rs.gov.br. Acessado em 10 de dezembro de 2008.

MÓSENA, Marlova. Agricultura em áreas frágeis: as transformações decorrentes do processo de arenização em São Francisco de Assis/RS. 2006. 143 f. Dissertação (Mestrado em Desenvolvimento Rural) - Programa de pós-graduação em Desenvolvimento Rural, Faculdade de Ciências Econômicas, Universidade Federal do Rio Grande do Sul, Porto Alegre, 2006.

RIBEIRO, José Carlos Corrêa. A Verticalização da Paisagem nos Campos de Areia da Vila Kraemer. São Francisco de Assis/RS. 2008. 187 f. Dissertação (Mestrado em Geografia) - Programa de pós-graduação em Geografia, Instituto de Geociências, Universidade Federal do Rio Grande do Sul, Porto Alegre, 2008.

SOUTO, J. J. P. Deserto, uma ameaça? Estudo dos núcleos de desertificação na fronteira sudoeste do Rio Grande do Sul. Porto Alegre: Secretaria da Agricultura, Departamento de Recursos Naturais Renováveis, 1985. $169 \mathrm{p}$.

SUERTEGARAY, Dirce M. A. A trajetória da natureza: um estudo geomorfológico sobre os areais de Quaraí-RS. São Paulo. Tese de Doutorado. 1987.

SUERTEGARAY, Dirce M. A; GUASSELLI, Laurindo A.; VERDUM, Roberto (Org.). Atlas da arenização: sudoeste do Rio Grande do Sul. Porto Alegre: Secretaria da Coordenação e Planejamento, 2001. 84 p.

\title{
SANDIZATION: VISION AND PRACTICES OF LOCAL TECHNICIANS AND MANAGERS IN SOUTHWESTERN RIO GRANDE DO SUL
}

\begin{abstract}
Since the 1970s, sandization and silviculture have been on the environmental issues agenda in Southwestern Rio Grande do Sul, spanning various segments of society, such as local agriculturalist and rancher communities, technicians and politicians. This article demonstrates some of the views of local technicians and managers in relation to the sandization, as well as soil conservation practices advocated by these. To obtain this information, structured interviews were conducted with thirty-nine technicians in fifteen municipalities: Alegrete, Manoel Viana, Maçambará, Quaraí, Rosário do Sul, Cacequi, Itaqui, Santiago, Unistalda, Jaguari, Santa Maria, Santana do Livramento, São Borja, Uruguaiana. Among the search results, we identified the widespread recommendation of planting trees, such as eucalyptus, and exotic pastures by local technicians and managers. Key words: sandization - silviculture - environmental policies - soil conservation.
\end{abstract}

